\title{
Matrix Converter Applied to Energy Saving for Street Lighting Systems
}

\author{
M. Román-Lumbreras ${ }^{1}$, G. Velasco-Quesada ${ }^{2}$, A. Conesa-Roca ${ }^{3}$ \\ Electronic Engineering Department, Technical University of Catalonia (UPC) \\ EUETIB - C. Urgell 187, 08036 - Barcelona (Spain) \\ ${ }^{1}$ Manuel. Roman@upc. edu \\ ${ }^{3}$ Guillermo.Velasco@upc.edu \\ ${ }^{2}$ Alfonso.Conesa@upc.edu
}

\begin{abstract}
This work presents a three-phase AC-AC converter, with independent phase control, based on matrixconverter structure. This converter is applied to electrical energy saving on the public lighting systems by means of regulation and control of the voltage applied to the lamps. The developed converter represents a technological improvement with respect to the traditional systems based on an autotransformer: it reduces system cost and volume, and increases lamps lifetime.
\end{abstract}

Keywords - AC-AC power conversion, Lighting, Lighting control, Pulse width modulated power converters.

\section{INTRODUCTION}

One area in which new technologies can provide great potential for savings is in street lighting systems. In this sense, the use of dimmable luminaries, instead classical lamps, improves the energy reduction about in $40-50 \%$. Nevertheless, the energy savings can be increased (around $70 \%$ ) if an "intelligent street lighting" system is used [1].

Systems for "intelligent street lighting" include dimmable luminaries, advanced lighting control, communication systems and administrative tools. This solution focuses on low energy consumption, high management capabilities and normally declines the maintenance costs for the operator. In most cases "intelligent street lighting", in its practical approach, is identical to "adaptive lighting", when this concept only describes the performance of the light on the road [2].

Among others capabilities, a basic adaptive lighting system must adjust the illumination level of a particular street according to their time pattern of utilization. The illumination level must be higher during hours of greater utilization and must fall gradually when its use decreases. This control of the illumination is realized by means of a power system that, following the established hourly program, controls the voltage applied to a group of conventional magnetic-ballast-driven HID lamps [3].

Accordingly, an important energy saving is obtained when the luminaries voltage is stabilized and reduced, because their power consumption is a square function of the applied voltage. This energy saving can be around $30-40 \%$ with respect to lighting systems that operate with constant voltage (constant level illumination) [3].

Traditionally, the voltage adjustment is implemented by several static AC controlled switches and a multiple-tapped autotransformer. The control system activates the appropriate switches and selects the autotransformer tap according to the desired AC voltage value to apply to the lamps [4], as shows Fig. 1. Some disadvantages of this system derive from the utilization of multiple-tapped autotransformers, because the use of this bulky, lossy (on low-dimming levels [3]) and expensive component implies a limited margin of regulation and a staggered output voltage. Fig. 2 shows a $45 \mathrm{kVA}$ threephase system (15kVA per phase) based on multiple-tapped autotransformer.

Street lighting systems can be considered as a three-phase system formed by three independent single-phase systems. This architecture implies the design of a three-phase system with independent voltage regulation for each phase. The adopted solution in this work consists in the use of three equal single-phase regulators, each of them connected between one phase and neutral node.



Fig. 1. Conventional voltage adjustment for street lighting systems



Fig. 2. 45kVA voltage regulator based on multiple-tapped autotransformer 
According to above considerations, a new AC voltage regulator adapted for the control of the public lighting systems is proposed. This regulator is based on a three-phase converter (formed by three single-phase matrix converters with independent phase control), with continuous regulation of the output voltage, with theoretical margin of regulation between $0-100 \%$ and without autotransformer.

However, the use of new technologies in these applications will produce large changes in the equipment used. For example, the development of high-power light emitting diode for street lighting is growing continuously owing to its greater energy efficiency, long operating life and light control [5].

\section{CONVERTER StruCture}

The matrix converter (MC) is a forced commutated ac-ac converter which uses an array of controlled bidirectional switches, as the main power elements, to create a variable output voltage system. It has no dc-link circuits and needs no large energy storage elements [6].

Fig. 3 (a) shows the topology of a single-phase MC, which implies the use of four bidirectional switches, and each one can be formed by two connected IGBTs, as shows Fig. 2 (b). This figure also includes the LC output filter [7].

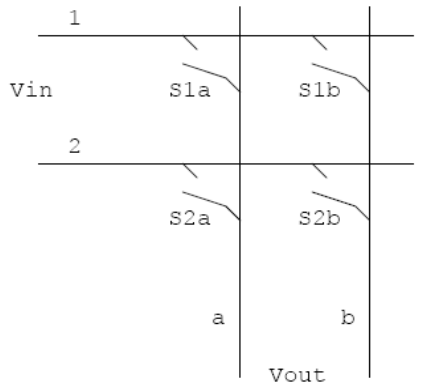

(a)

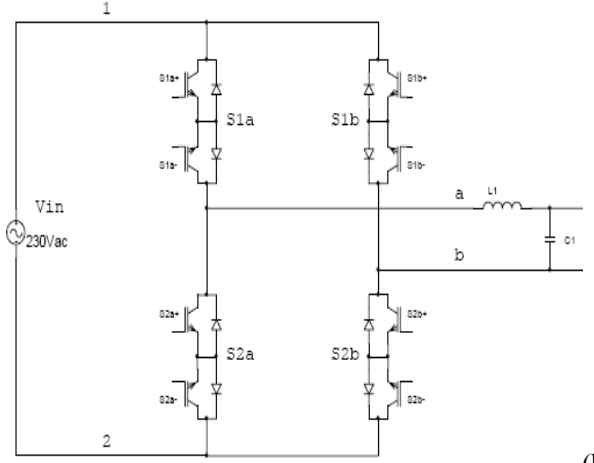

(b)

Fig. 3. Single-phase MC: (a) Topology and (b) Switches implementation

The general case of operation for the MC can be described as follows:

$$
\left(\begin{array}{l}
V_{a} \\
V_{b}
\end{array}\right)=\left(\begin{array}{ll}
m_{1 a} & m_{2 a} \\
m_{1 b} & m_{2 b}
\end{array}\right) \cdot\left(\begin{array}{l}
V_{1} \\
V_{2}
\end{array}\right)
$$

where: $m_{1 a}+m_{2 a}=1$, and $m_{1 b}+m_{2 b}=1$, being $0<m_{i j}<1$, $i=1,2$ and $j=a, b$.
For the described application, it is necessary that one of the output nodes of each converter must be connected to the neutral node of the output voltage regulated system. This connection is not possible if the MC structure on Fig. 3 is used, because, under normal operation, none of the two output nodes of the converter can be common to all three phases without short-circuiting them [8].

For this reason, in expression (1) $V_{2}=V_{b}$ is imposed and so:

$m_{1 b}=0, m_{2 b}=1$ and $\left(\begin{array}{l}V_{a} \\ V_{b}\end{array}\right)=\left(\begin{array}{cc}m_{1 a} & m_{2 a} \\ 0 & 1\end{array}\right) \cdot\left(\begin{array}{l}V_{1} \\ V_{2}\end{array}\right)$

That implies: $V_{a}=m_{1 a} \cdot V_{1}+m_{2 a} \cdot V_{2}$.

Thus, it is possible to write:

$$
\begin{aligned}
& V_{a b}=V_{a}-V_{b}=m_{1 a} \cdot V_{1}+m_{2 a} \cdot V_{2}-V_{2}=m_{1 a} \cdot V_{1}-\left(1-m_{2 a}\right) \cdot V_{2} \\
& \Rightarrow \quad V_{a b}=m_{1 a} \cdot\left(V_{12}\right)
\end{aligned}
$$

This analysis leads to the converter structure finally proposed, and shown in Fig. 4. In this case, the S2b switch is replaced by a short circuit and the $\mathrm{S} 1 \mathrm{~b}$ switch by an open circuit, obtaining a structure similar to the Buck converter, but utilizing bidirectional switches.

In the structure, input node 2 (which coincides with output node $b$ ) will be the neutral node.

This methodology is extended to three-phase systems and it leads to the converter presented in Fig. 5. The proposed threephase converter is formed by three independent single-phase converters, connected to the three-phase four wires $400 \mathrm{~V} /$ $50 \mathrm{~Hz}$ distribution network.

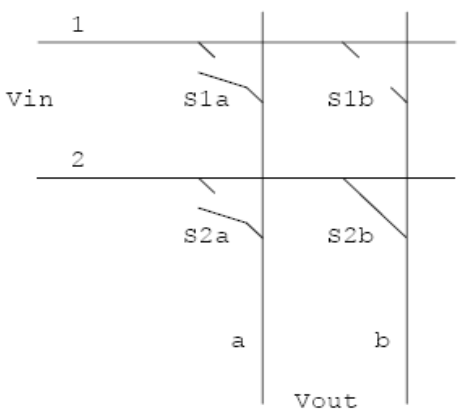

(a)

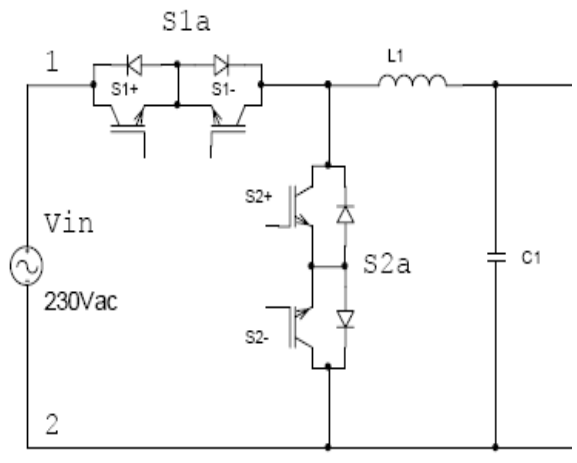

(b)

Fig. 4. Proposed single-phase MC: (a) Topology and (b) Implementation 


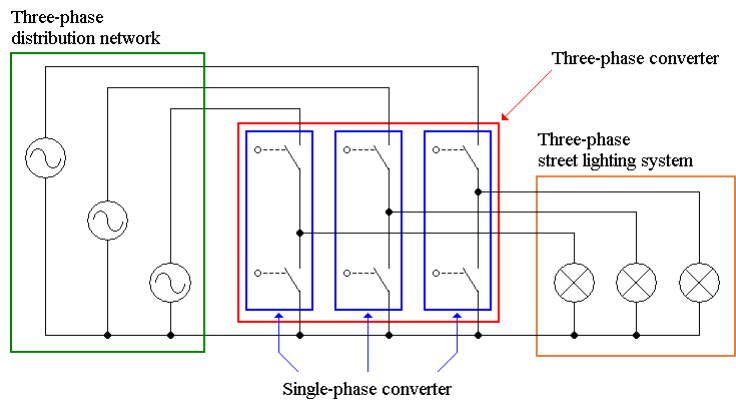

Fig. 5. Topology of the proposed three-phase converter

Fig. 6 shows the simulation results for the output voltage of the MC before the LC output filter. The voltage is unidirectional with values between $V_{\text {in }}$ and zero. This feature is relevant for the control strategy of the system.

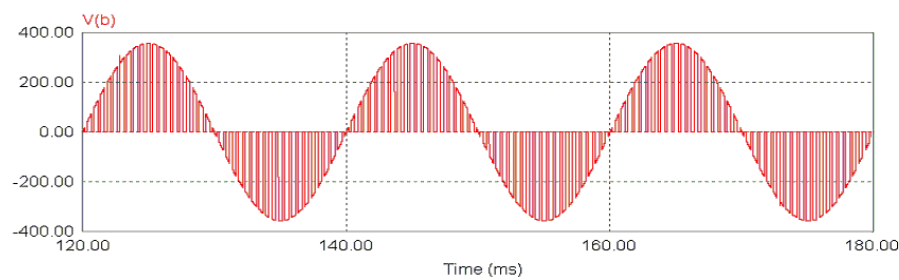

Fig. 6. Output waveforms of the converters before filter LC

\section{CONTROL STRATEGY}

The output voltage of the converter after the LC output filter is obtained as the average value of the voltage applied to the filter. Considering equation (3) and according to [9], it is possible to affirm that:

$$
u_{o}(t)=m_{1 a} \cdot u_{i}(t)
$$

being: $m_{1 a}=D=\frac{T_{O N}}{T}$, and $u_{i}(t)=U_{i \max } \cdot \operatorname{sen}(\omega t)$

If the value of the duty cycle $(D)$ stays constant during all the commutations, then:

- The waveform of the output voltage $u_{o}(t)$ is equal to the waveform of the input voltage $u_{i}(t)$

- The RMS value of the output voltage is directly proportional to the value of the duty cycle $(D)$

Thus, both the converter control mode and the components calculation of the LC output filter are similar to those applied in the case of a DC-DC Buck converter design.

\section{CONVERTER OPERATION}

Each lamp group is driven in order to compensate for reactive power and therefore, in steady state, the power factor is close to the unit. However, during the ignition of the lamp, the current can reach values close to twice the rated current, and with a considerable reactive component.

Fig. 6 shows voltage and current on $13 \mathrm{kVA}$ set of mercuryvapor HID lamps: a) ignition period and b) stabilized operation, after three minutes from the ignition.

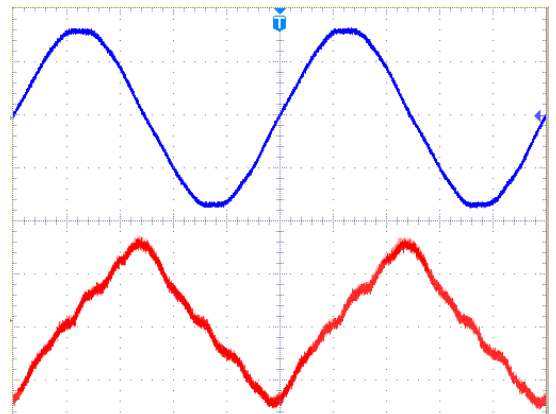

Ch1 $2.00 \mathrm{~V}$ ch2 $200 \mathrm{mV}$ P $4.00 \mathrm{~ms}$ A Ch1 S $80.0 \mathrm{mV}$

(a)

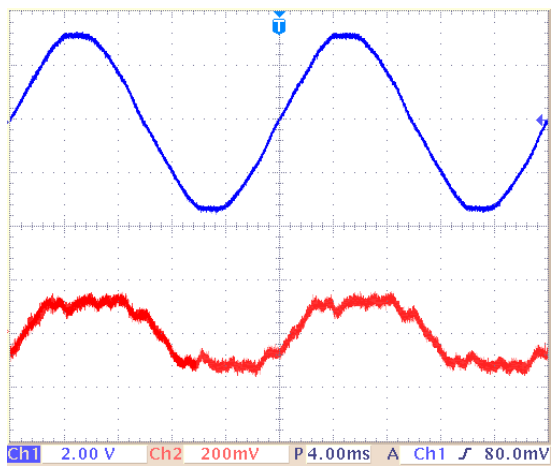

(b)

Fig. 7. Experimental waveforms of voltage and current on lamps: (a) power up and (b) steady state. Scales: Voltage $=200 \mathrm{~V} / \mathrm{div}$, Current $=100 \mathrm{~A} / \mathrm{div}$, Time $=4 \mathrm{~ms} / \mathrm{div}$

The converter must be able to work with reactive load and must guarantee bidirectional current on the load for a desired output voltage. Then, the signs of the waveforms of the output voltage and load current can be different, and the switches must guarantee each combination. Fig. 8 shows different switches activations in order to set an output voltage for a positive ( $\mathrm{a}$ and $\mathrm{b}$ ) or negative ( $\mathrm{c}$ and $\mathrm{d}$ ) load current.



(a)

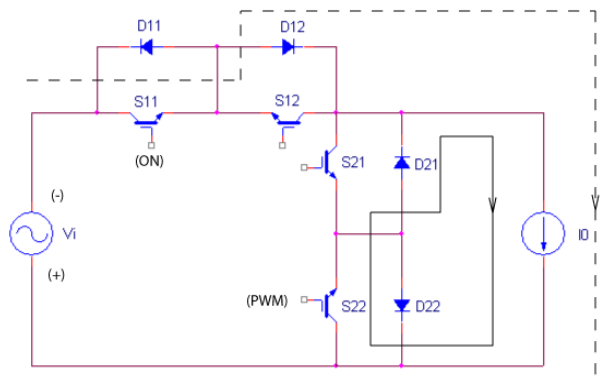

(b) 


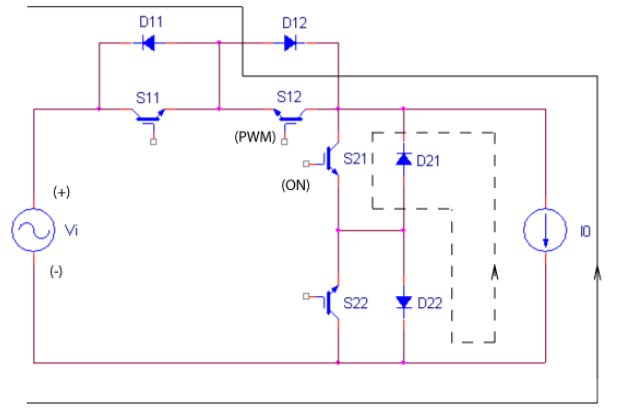

(c)

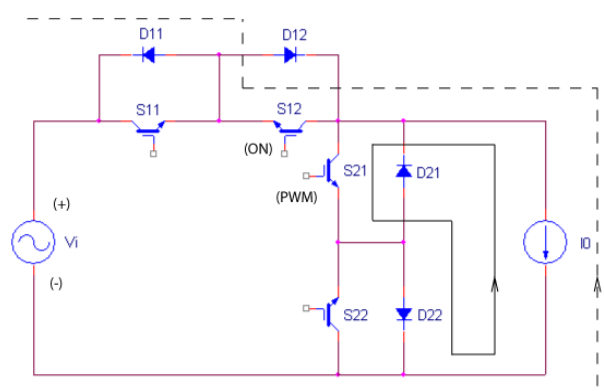

(d)

Fig. 8. Two operation sequences of the converter with inductive load: (case ab) positive output current and (case c-d) negative output current

\section{SimUlation RESUltS}

The converter has been simulated with PSIM software. Figs. 9 and 10 show the results obtained from the simulation, using a resistive load of $3 \mathrm{~kW} / 230 \mathrm{~V}$, an input voltage of $230 \mathrm{~V}$ and an output voltage of $185 \mathrm{~V}$. In this sense, these simulation results are in accordance with the analysis presented previously.

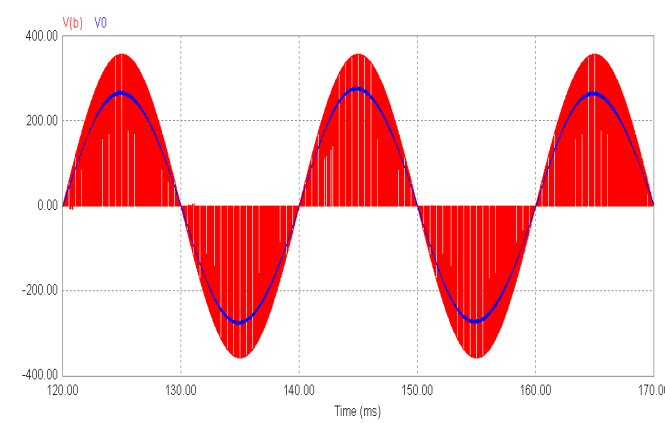

(a)

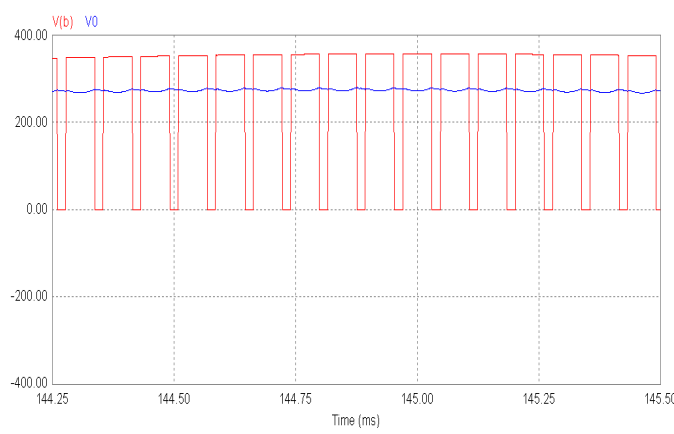

(b)

Fig. 9: (a) Voltage waveforms before (red colour) and after (blue colour) the LC output filter. (b) Waveforms detail

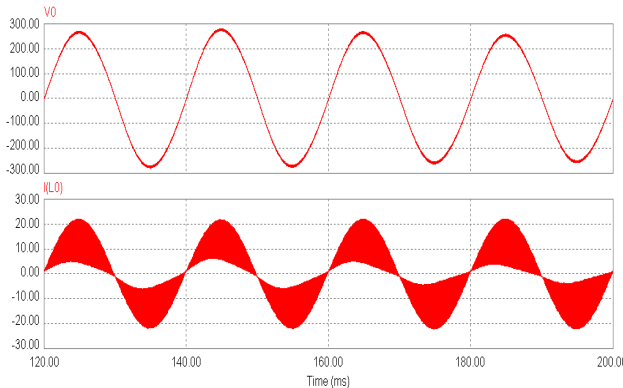

(a)

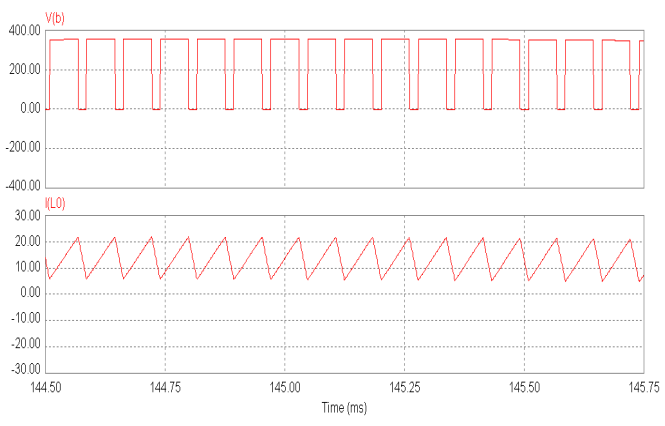

Fig. 10: (a) On top waveform: Voltage after the LC output filter. On bottom waveform: Inductor current. (b) Waveforms details

\section{EXPERIMENTAL RESULTS}

A $45 \mathrm{kVA}$ three-phase converter has been constructed with three independent $15 \mathrm{kVA}$ single-phase converters. The switching frequency of the converter is $13 \mathrm{kHz}$. The prototype has been tested and the experimental results agree with the simulations and the analysis developed. The prototype accomplishes the desired functionality for its application on energy saving in street lighting systems.

Fig. 11 shows the $15 \mathrm{kVA}$ single-phase prototype. The $45 \mathrm{kVA}$ three-phase converter will correspond to three singlephase converters with the neutral node connected.

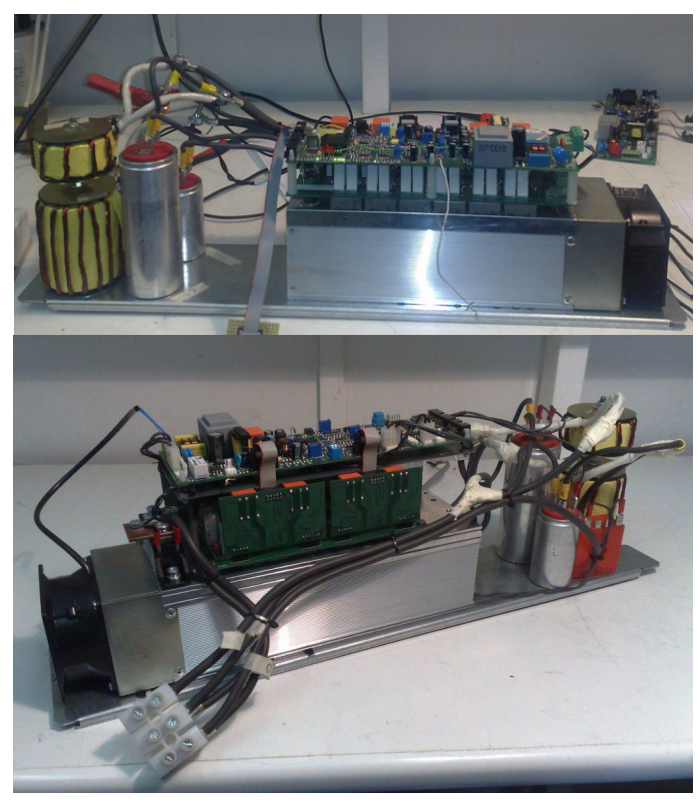

Fig. 11. 15kVA single-phase converter prototype 
Figs. 12 and 13 show the most significant waveforms on the prototype, using a resistive load as employed in the simulations $(3 \mathrm{~kW} / 230 \mathrm{~V} / 50 \mathrm{~Hz})$. These waveforms agree with those obtained by simulation.

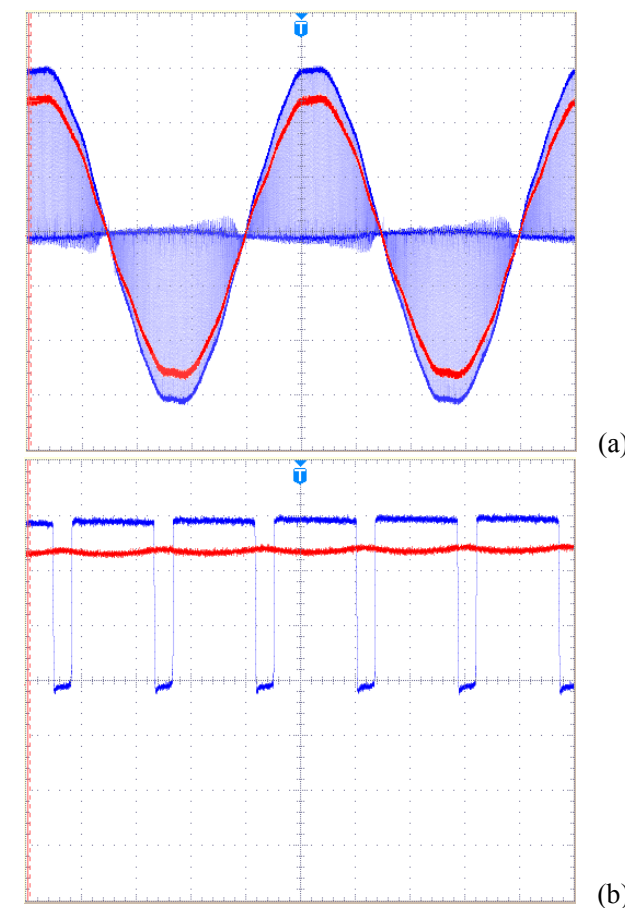

(b)

Fig. 12: (a) Voltage waveforms before (blue colour) and after (red colour) the output LC filter. (b) Waveforms detail. Scales: Voltage $=200 \mathrm{~V} / \mathrm{div}$, Time (a) $=4 \mathrm{~ms} / \mathrm{div}$, Time $(\mathrm{b})=50 \mu \mathrm{s} / \mathrm{div}$

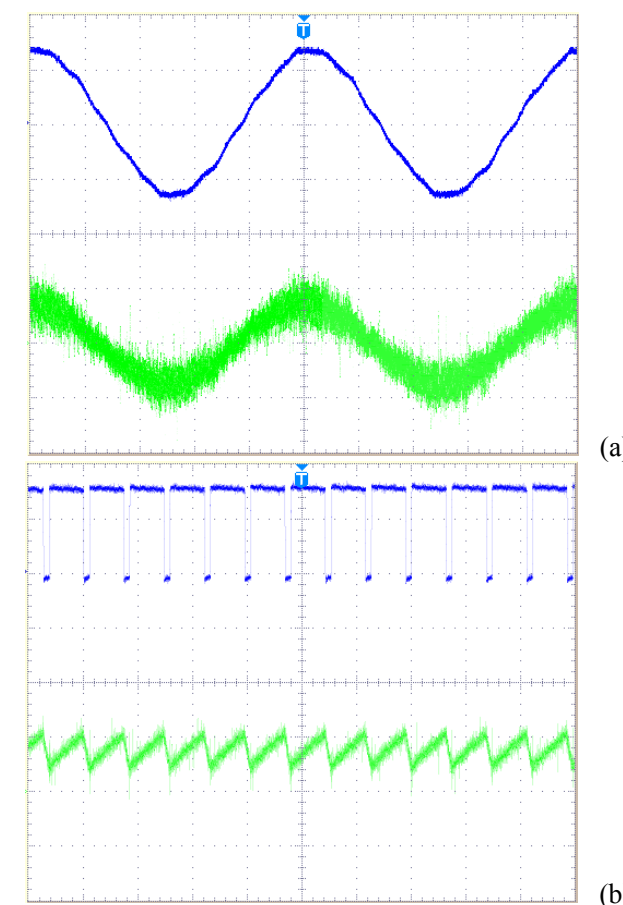

(a)

(b)

Fig. 13: (a) On top waveform: Voltage after the output LC filter. On bottom waveform: Inductor current. (b) Waveforms detail. Scales: Voltage $=$ $200 \mathrm{~V} / \mathrm{div}$, Current $=20 \mathrm{~A} / \mathrm{div}$, Time (a) $=4 \mathrm{~ms} / \mathrm{div}$, Time $(\mathrm{b})=100 \mu \mathrm{s} / \mathrm{div}$

\section{CONCLUSIONS}

This paper presents a three-phase matrix converter, constructed by the association of three single phase converters with a common point (neutral). This converter is applied to the voltage control of public lighting systems for energy saving purposes. This system might replace the conventional systems based on the utilization of AC switches and a multiple-tapped autotransformer. The use of this kind of converters can improve the efficiency of the street lighting system, because it allows the process of lighting control automation and increase the flexibility and versatility of the system.

The topology derived from the matrix converter theory is a simplified single-phase topology. This topology reduces the number of the used semiconductors and permits to connect the three single-phase converters to a single common point (neutral).

Finally, a prototype of one-phase converter of $15 \mathrm{kVA}$ has been constructed. In this prototype, the behavior of the converter has been verified in real operating conditions, and the obtained results are fully consistent with those obtained by simulation.

\section{ACKNOWLEDGEMENTS}

This work has been developed in collaboration with MIMAVEN ELECTRICA S.A. This company has more than 30 years of experience developing and manufacturing electromagnetic components and power electronic systems.

\section{REFERENCES}

[1] Intelligent Energy Europe, "Guide for energy efficient street lighting installations" European Commission - Executive Agency for Competitiveness \& Innovation (EACI), 2007.

[2] Intelligent Energy Europe, "Project Report. Intelligent Road and Street lighting in Europe" European Commission - Executive Agency for Competitiveness \& Innovation (EACI), 2008.

[3] Wei Yan and Hui S.Y.R., "Dimming Characteristics of Large-scale High-Intensity-Discharge (HID) Lamp Lighting Networks using to Energy-Saving Power station System" in Proc. IEEE Industry Applications Conference, 2006, Vol. 3, pp. 1090-1098

[4] Chung H.S.H., Ho N.M., Hui S.Y.R and Mai W.Z., "Case study of A High-Reliable Dimmable Road Lighting System with Intelligent Remote Control" in Proc. 11th European Conference on Power Electronics and Applications, 2005.

[5] Long X., Liao R. and Zhou J., "Development of street lighting systembased novel high-brightness LED modules" Optoelectronics, IET , vol.3, no.1, pp.40-46, February 2009.

[6] Bradaschia F., Cavalcanti M.C., Neves F. and de Souza H., "A Modulation Technique to Reduce Switching Losses in Matrix Converters" Industrial Electronics, IEEE Transactions on, vol.56, no.4, pp.1186-1195, April 2009.

[7] Imayavaramban M., Latha K. and Uma G., "Analysis of Different Schemes of Matrix Converter with Maximum Voltage Conversion Ratio" in Proc. 12th IEEE Mediterranean Electrotechnical Conference, 2004, Vol. 3, pp. 1137-1140.

[8] Idris Z., Mohammad Noor S.Z. and Hamzah M.K., "Safe Commutation Strategy in Single Phase Matrix Converter" in Proc. International Conference on Power Electronics and Drives Systems, 2005, Vol. 2, pp. 886-891.

[9] Hamzah M.K., Mohammad S.Z and Abdul S.F., "A New Single-Phase Inverter using Single-Phase Matrix Converter Topology" in Proc. IEEE International Power and Energy Conference, 2006, pp. 459-464. 